https://helda.helsinki.fi

The dynamic interplay between merger process justice and cognitive trust in top management : A longitudinal study

Kaltiainen, Janne Petteri

2017-04

Kaltiainen , J P , Lipponen , J M T \& Holtz , B C 2017 , ' The dynamic interplay between merger process justice and cognitive trust in top management : A longitudinal study ' , Journal of Applied Psychology, vol. 102 , no. 4 , pp. 636-647 . https://doi.org/10.1037/apl0000180

http://hdl.handle.net/10138/183975

https://doi.org/10.1037/apl0000180

acceptedVersion

Downloaded from Helda, University of Helsinki institutional repository.

This is an electronic reprint of the original article.

This reprint may differ from the original in pagination and typographic detail.

Please cite the original version. 
APA copyright notice: This article may not exactly replicate the authoritative document published in the Journal of Applied Psychology. It is not the copy of the record. www.apa.org http://dx.doi.org/10.1037/apl0000180

\title{
The Dynamic Interplay Between Merger Process Justice and Cognitive Trust in Top Management: A Longitudinal Study
}

\author{
Janne Kaltiainen and Jukka Lipponen \\ University of Helsinki \\ Brian C. Holtz \\ Temple University
}

Corresponding author: Janne Kaltiainen, janne.kaltiainen@helsinki.fi

Author Note.

Janne Kaltiainen, Department of Social Research, University of Helsinki; Jukka Lipponen, Department of Social Research, University of Helsinki; Brian C. Holtz, Fox School of Business, Temple University.

Early versions of this article were presented at the 2016 Society for Industrial and Organizational Psychology conference and the 2016 International Society for Justice Research conference. This research was supported by the Finnish Work Environment Fund, grant 113090 awarded to Jukka Lipponen and grant 115306 awarded to Janne Kaltiainen. We thank our colleagues Olli-Jaakko Kupiainen and Marko Hakonen for their important role in the research project, and Crystal Harold and Jesse Haapoja for their input and feedback regarding the manuscript. 


\begin{abstract}
This study examines two fundamental concerns in the context of organizational change: employees' perceptions of merger process justice and cognitive trust in the top management team. Our main purpose is to better understand the nature of reciprocal relations between these important constructs through a significant change event. Previous research, building mainly on social exchange theory, has framed trust as a consequence of justice perceptions. More recently, scholars have suggested that this view may be overly simplistic and that trust-related cognitions may also represent an important antecedent of justice perceptions. Using three-wave longitudinal survey data $(N=622)$ gathered during a merger process, we tested reciprocal relations over time between cognitive trust in the top management team and perceptions of the merger process justice. In contrast to the conventional unidirectional notion of trust or trustrelated cognitions as outcomes of perceived justice, our results show positive reciprocal relations over time between cognitive trust and justice. Our findings also revealed that the positive influence of cognitive trust on subsequent justice perceptions was slightly more robust than the opposite direction. By examining cross-lagged longitudinal relations between these critical psychological reactions, this study contributes across multiple domains of the management literature including trust, justice, and organizational mergers.
\end{abstract}

Keywords: Mergers \& acquisitions; justice/fairness; trust; leadership; longitudinal study 
Scholars have accumulated considerable evidence regarding the benefits of fostering favorable perceptions of justice and trust in organizations. For instance, meta-analytic evidence indicates that trust and justice constructs are significantly associated with a similar set of outcomes including job satisfaction, task performance, citizenship behavior, and turnover (e.g., Colquitt et al., 2013; Dirks \& Ferrin, 2002; Rupp, Shao, Jones, \& Liao, 2014). Despite the wealth of research focused on issues of organizational justice and trust, the nature of relations between these constructs "remains poorly understood" and the extant literature has been "marked by the deceptively uncontroversial notion that justice leads to trust" (Colquitt \& Rodell, 2011, p. 1202). With this in mind, recent conceptual advances suggest that these constructs should have positive reciprocal relations over time (Holtz, 2013). That is, trust cognitions at one point in time may shape subsequent justice perceptions and those justice perceptions may, in turn, impact later trust cognitions (and vice versa). Empirically, however, the possibility of feedback loops, or reciprocity, between justice and trust variables remains largely untested.

The primary goal of the current study is to help elucidate the reciprocal relations between justice and trust variables over time. We examine these relations in a three-wave, cross-lagged, longitudinal study of employees experiencing an organizational merger. The study context is important because the effective management of employee perceptions of trust and fairness is vital to the success of organizational mergers (Giessner, Ullrich, \& van Dick, 2012; Stahl, Larsson, Kremershof, \& Sitkin, 2011) and questions of trust and fairness are particularly salient during change events (Dirks \& Ferrin, 2002; Li, 2012; Lind, 2001).

Establishing a more complete understanding concerning the dynamic relations between trust and justice is important if the research literature is to provide sound guidance for the effective management of employee reactions to significant organizational events (Holtz, 2015). This study provides the first empirical test of reciprocal relations between 
justice and trust variables assessed across more than two time points (i.e., justice $\rightarrow$ trust $\rightarrow$ justice; trust $\rightarrow$ justice $\rightarrow$ trust). Furthermore, to strengthen our inference regarding the over time relations and causality, we control for the effect of prior level of the dependent variable in our analyses (Cole \& Maxwell, 2003; Holtz, 2013; Little, 2013). In addition, this study answers calls for more longitudinal research into the temporal dynamics of justice perceptions (e.g., Fortin, Cojuharenco, Patient, \& German, 2016; Rupp et al., 2014) and for research to consider the role of trust cognitions in shaping justice perceptions (e.g., Colquitt \& Rodell, 2011; Lewicki, Wiethoff, \& Tomlinson, 2005). Finally, we address calls for research to better understand how employees' psychological reactions unfold throughout a merger process (e.g., Monin, Noorderhaven, Vaara, \& Kroon, 2013; Nemanich \& Keller, 2007).

\section{Organizational Justice and Trust Cognitions}

The organizational justice literature delineates several key justice facets including perceptions of outcome allocations (distributive justice), procedures (procedural justice), explanations (informational justice), and interpersonal treatment associated with the implementation of procedures and outcomes (interpersonal justice; Colquitt \& Shaw, 2005). However, because employees naturally consider fairness issues in a more holistic sense (Ambrose \& Schminke, 2009; Greenberg, 2001; Shapiro \& Kirkman, 2001), and facet measures are often highly correlated, it is often prudent to combine facets into a composite justice construct, unless there are strong theoretical grounds to expect unique effects across justice facets (Ambrose \& Arnaud, 2005; Colquitt \& Rodell, 2015; Holtz, 2013). Currently, there is no theoretical basis to expect differential relations between specific facets of justice constructs and cognitive trust (Holtz, 2013). Therefore, we focus on aggregate perceptions of the formal procedures, explanations, and interpersonal treatment, or perceived "process 
fairness" of an organizational merger in this study (e.g., Bobocel \& Gosse, 2015; Brockner, Wiesenfeld, \& Diekmann, 2009; Lind \& Tyler, 1988). ${ }^{1}$

Organizational scholars have also conceptualized trust variables in different ways (McEvily \& Tortoriello, 2011). For instance, McAllister (1995) described that trust may focus on emotional connections (affective trust) or determinations of an entity's competence and responsibility (cognitive trust). We focus on cognitive trust evaluations in this study for two reasons. First, building on organizational change research (e.g., Lines, Selart, Espedal, \& Johansen, 2005; Tyler \& De Cremer, 2005), we reasoned that the complexity involved in planning and implementing a large-scale merger should make concerns regarding the competence of the relevant decision-makers (i.e., the top management team) particularly salient in the minds of affected employees. Second, rank and file employees would not likely have the opportunity to develop close interpersonal relationships (affective trust) with the top management team overseeing the merger process. Furthermore, it is important to clarify that cognitive trust is conceptually distinct from the psychological state of trust, which reflects a general willingness to be vulnerable to the actions of another party (Mayer, Davis, \& Schoorman, 1995; Rousseau, Sitkin, Burt, \& Camerer, 1998). Given that the relevant research literature has not consistently distinguished between different trust concepts (Colquitt, Scott, \& LePine, 2007), we use the term trust-related cognitions to encompass research involving trust concepts generally.

\section{Justice as an Antecedent of Trust-Related Cognitions}

Among the various theoretical frameworks that can be utilized to investigate justice phenomena, social exchange theory (Blau, 1964) has been the most dominant perspective for explaining how justice influences trust-related cognitions in employment relationships (Colquitt \& Rodell, 2011). The relevance of social exchange theory for understanding justicetrust relations has been detailed extensively in previous reviews (Cropanzano \& Mitchell, 
2005; Cropanzano \& Rupp, 2008). Social exchange theory is based on the idea of reciprocity: being treated in a favorable way by an exchange partner creates an obligation to reciprocate in a similarly positive manner (Blau, 1964). Successfully reciprocated exchanges help to demonstrate that one is trustworthy and gradually build trust between exchange partners over time (Blau, 1964; Cook, 2005; Molm, Takahashi, \& Peterson, 2000). While there are myriad possible social exchange considerations, authors have suggested that fairness is particularly important for cultivating positive exchange relationships (e.g., Blader \& Tyler, 2005; Colquitt \& Zipay, 2015; Dirks \& Ferrin, 2002; Moorman \& Byrne, 2005). Therefore, when the leaders of an organization treat employees fairly, employees tend to reciprocate with positive attitudes and believe their leaders are trustworthy.

A large empirical literature, including several meta-analytic studies (Cohen-Charash \& Spector, 2001; Colquitt et al., 2013; Dirks \& Ferrin, 2002; Rupp et al., 2014), supports the notion that employee perceptions of justice are positively related to trust-related cognitions. Consistent with social exchange theory (Blau, 1964) and relevant research findings (e.g., Colquitt et al., 2013), we expect that a top management team's use of fair treatment and procedures when planning and implementing an organizational merger will be related to employees' beliefs that the team is competent and reliable (cognitive trust).

Hypothesis 1. Process justice perceptions will have a positive relationship with subsequent cognitive trust, controlling prior cognitive trust.

\section{Justice as an Outcome of Trust-Related Cognitions}

Although conventional wisdom suggests that justice perceptions influence trustrelated cognitions, historically, this relationship has not received sufficient scrutiny and there is reason to suspect that trust-related cognitions play an important role in shaping perceptions of justice (Colquitt \& Rodell, 2011; Lewicki et al., 2005). For instance, the trust primacy model (Holtz, 2013) argues that trust-related cognitions inevitably exert significant influence 
on employee perceptions of justice. More specifically, the psychological phenomenon of confirmation bias is key to understanding why trust-related cognitions may impact employee perceptions (Dirks \& Ferrin, 2001; Kramer, 2009; Robinson, 1996).

Confirmation bias represents the fundamental tendency for people to perceive and interpret information in a manner that reinforces their preconceived expectations or beliefs (e.g., Evans, 1989; Fiske \& Taylor, 1991; Nickerson, 1998; Snyder \& Swann, 1978). Simply stated, people generally see what they expect to see (Shapiro \& Kirkman, 2001). A person who believes a trustee is incompetent (low cognition-based trust) will likely to perceive a lack of process fairness (e.g., capricious decisions, inadequate explanations, etc.) permeating through actions of the trustee because such perceptions would validate the trustor's expectations of incompetence. Conversely, expectations that a trustee is highly competent (high cognition-based trust) may predispose one towards seeing signs of favorable process fairness (e.g., judicious decisions, reasonable explanations, etc.) in the actions of the trustee. Thus, trust-related expectations may color justice perceptions in a manner consistent with principles of confirmation bias (Holtz, 2013; Shapiro \& Kirkman, 2001). In this manner, "distrust may become the source of its own evidence" (Gambetta, 1988, p. 234).

As presented earlier, meta-analytic research suggests that trust-related cognitions are positively correlated with justice perceptions (e.g., Colquitt et al., 2013). However, past estimates are largely derived from cross-sectional studies that preclude causal inferences (Holtz, 2013). In recent years, some multi-wave studies have sought to test the effect of trustrelated cognitions on justice perceptions. For instance, a longitudinal survey study by Holtz and Harold (2009) found that organization-focused and supervisor-focused trust predicted overall justice perceptions over time. Similarly, a series of experimental studies by Holtz (2015) suggested that pre-event trustworthiness evaluations had positive effects on post-event justice perceptions. Taken together, we expect that higher levels of cognitive trust in the top 
management team will predispose employees towards perceiving the actions of the top management team in a more favorable light.

Hypothesis 2. Cognitive trust will have a positive relationship with subsequent perceptions of process justice, controlling prior process justice perceptions.

\section{Reciprocal Relations Over Time}

Scholars have suggested that trust and other psychological constructs tend to have reciprocal relations over time (Andersson \& Pearson, 1999; Chan \& McAllister, 2014; Ferguson \& Peterson, 2015). For instance, Holtz's (2013) trust primacy model describes a reciprocal relationship such that evaluations of trustworthiness will shape how one perceives subsequent justice-related events and then those event justice perceptions, in turn, will affect subsequent trustworthiness evaluations. Likewise, Lewicki et al. (2005) proposed trust and justice as co-developing constructs that influence each other over time.

While there are theoretical reasons to expect reciprocal relations between trust-related cognitions and justice constructs, research has not fully examined this proposition. Research by Colquitt and Rodell (2011) represents the only test of reciprocal relations between justice and trust constructs. Their results suggested that employee evaluations of their supervisor's integrity and interpersonal justice were positively, reciprocally, related across two time points. However, cross-lagged estimates between procedural, informational and interpersonal justice perceptions (i.e., process fairness) and evaluations of supervisors' competence and reliability (i.e., cognitive trust) were not significant in their sample. Though this study provides important insights, there is still need for further investigation. For instance, the use of more than two time points can allow for stronger inferences regarding the possibility of reciprocal causality between variables (Farrell, 1994; Little, 2013; Ployhart \& Vandenberg, 2010). Additionally, Colquitt and Rodell's study was not tied to any particular event or context. An organizational merger provides an ideal context to study reciprocal relations 
between trust and justice constructs because mergers represent dynamic events that are associated with high uncertainty (Dirks \& Ferrin, 2002; van den Bos, 2001). Consistent with extant theoretical arguments (Holtz, 2013; Lewicki et al., 2005) we hypothesize:

Hypothesis 3. Process justice perceptions and cognitive trust have positive reciprocal relations over time. Specifically, planning stage (Time 1) process justice (cognitive trust) perceptions will have a positive relationship with subsequent postmerger (Time 2) cognitive trust (process justice) perceptions, which in turn will have a positive relationship with later post-merger (Time 3) process justice (cognitive trust) perceptions.

\section{Method}

\section{Sample and Procedure}

This study took place in the context of a merger between two civil service organizations in Finland. In total, approximately 15,000 employees were affected by this merger. Three online surveys were administered at successive one-year intervals (see Figure 1) to provide sufficient time to capture the psychological experiences of employees through the full merger process. The three surveys were completed by $3,679,1,181$, and 623 respondents, respectively. ${ }^{2}$ One respondent was on the top management team and was excluded from the dataset. Thus, the final sample included 622 employees matched across three time points. At Time 1, the average participant was 47.5 years old with between 13 to 15 years of organizational tenure. The majority of participants were female (88\%) and had the equivalent of a bachelor's degree or higher $(57 \%)$. This the first use of the data collected as part of a larger organizational study which had been granted research permissions by the participating organizations.

It is important to note that unlike most private sector mergers, this change was mandated by a municipal council. The organizations' top management team did not control 
the initial merger decision, but they were explicitly responsible for planning and implementing the organizational merger. At the time of the first survey, employees knew that the merger was going to occur but did not have specific information concerning the outcomes of the merger for them personally. The principle changes associated with the merger, which took approximately six months, were carried shortly after the first survey and they were finished several months before the second survey (see Figure 1 for description of the merger phases involved in this study).

\section{Measures}

Descriptive statistics for the study's constructs are presented in Table 1. Unless stated otherwise, items were assessed on a 5-point scale $(1=$ completely disagree $; 5=$ completely agree). A full list of items is presented in Appendix.

Merger process justice. We measured the perceived merger process justice using six items modified from Moorman (1991) and Mansour-Cole and Scott (1998). Items focused on the fairness of the decision-making process and implementation of the procedures during the merger. Thus, the measurement referent was the merger process event. The measurement consisted of items tapping into procedural (fairness of procedures), informational (accuracy and quality of explanations), and interpersonal (given respect and concern) justice dimensions.

Cognitive trust in top management team. We measured cognitive trust in the top management team by using four items adapted from Mayer and Davis (1999) that tapped into the competence and reliability evaluation of the top management team, which included the head of the organization and head of divisions. ${ }^{3}$ At each measurement time point, the referent of the cognitive trust measurement was the current top management team. In between the one-year intervals of the data collection, changes occurred in the top management team. Between Time 1 and Time 2, eleven out of the twelve members of the top management were 
replaced or discharged. Between Time 2 and Time 3, two out of the seven managers in the top management team changed.

Control variables. Previous studies have shown that in addition to justice perceptions, outcome favorability can affect the level of trust towards authorities (e.g., Brockner, Siegel, Daly, Tyler, \& Martin, 1997). Therefore, we controlled for the effect of post-merger perceptions of outcome favorability in our analyses. Outcome favorability was measured on a 7 -point scale $(1=$ mostly negative $7=$ mostly positive $)$. Furthermore, we controlled for three time-invariant variables. Pre-merger organization $(0=\operatorname{organization} A, 1$ $=$ organization $B$ ) was controlled for as a merger process can be experienced and perceived differently depending to which merging organization an employee belongs to (e.g., Giessner et al., 2012). In addition, we controlled for the participant's position in the organization $(0=$ employee, 1 =supervisor or middle manager) as the higher-level employees can have a different viewpoint on the merger process and the top management team, and as prior research has shown that justice perceptions vary as a function of hierarchical level in the organization (Schminke, Cropanzano, \& Rupp, 2002). Finally, age was controlled for as prior studies have shown that trustworthiness (Sutter \& Kocher, 2007) and justice perceptions (Janssen, 2004) may vary as a function of age.

\section{Data Analysis}

We used structural equation modeling in Mplus 7.2 (Muthén \& Muthén, 2012) to estimate models with latent factors. Covariances among the items' residuals over time were estimated as recommended for longitudinal structural equation modeling (e.g., Little, 2013; Ployhart \& Vandenberg, 2010). Models were estimated using the maximum likelihood estimation with robust standard errors due to non-normality in the indicators. All the model comparisons were conducted by using Satorra-Bentler scale corrected chi-square difference test (Satorra \& Bentler, 2001). 
First, we conducted confirmatory factor analyses to determine if merger process justice was empirically distinct from our measure of cognitive trust in the top management team at all the three time points. A single-factor model, where all ten items loaded onto one factor at each of the three time points, resulted in a poor fitting model, $\chi^{2}(372)=2511.62, p<$ .001 , Comparative Fit Index $(\mathrm{CFI})=.81$, Tucker-Lewis Fit Index $(\mathrm{TLI})=.78$, Root Mean Square Error of Approximation $(\mathrm{RMSEA})=.10$, Standardized Root Mean Square Residual $(\mathrm{SRMR})=.11$. A two-factor model, where process justice and cognitive trust items loaded onto two separate factors, as shown in Table 2, provided improved and excellent fit to our data, $\chi^{2}(360)=535.70, p<.001, \mathrm{CFI}=.98, \mathrm{TLI}=.98, \mathrm{RMSEA}=.03, \mathrm{SRMR}=.03 . \mathrm{In}$ addition, the difference between these two models was statistically significant, $\Delta \chi^{2}(12)=1351.41, p<$ .001. To conclude, the excellent model fit of the proposed two-factor structure indicates that the two factors - process justice and cognitive trust — exist in the data, and the same items load onto the two distinct factors at all the three measurement time points. ${ }^{4}$

Next, to verify that the possible changes in the latent factors are not due to changes in the nature of the construct (e.g., membership in the top management), we tested for measurement invariance over time to verify that the same construct was operationalized by using the same set of measures at each of the three time points (Little, 2013; Vandenberg \& Lance, 2000). First, a configural invariance model of the two-factor structure, as described above and without placing any constraints, was assessed (Table 3). In the second step, a test of weak invariance was carried out by constraining factor loadings equal over time. As the decrease in model fit in comparison to configural model was not statistically significant, the weak invariance was established. As the final step, we estimated strong invariance by constraining also the item intercepts equal across time. A significant chi-square difference in comparison to a model with weak invariance, $\Delta \chi^{2}(16)=108.42, p<.001$, indicated some level of noninvariance among items' intercepts. We established partial strong invariance by 
not constraining the five item intercepts (item 4 of process justice at Time 1, Time 2 and Time 3; item 5 of process justice at Time 3; item 4 of cognitive trust at Time 3; see Table 2) equal over time. As the partial strong invariant model is in accordance with the recommended criteria (Byrne, 2012; Little, 2013), we concluded that the model indicated sufficient measurement invariance over time and proceeded to investigate over time relations between the variables.

\section{Results}

As an analysis method, we estimated a longitudinal cross-lagged panel model with latent factors. The time-invariant control variables (pre-merger organization, position in the organization, age) were regressed on justice and cognitive trust factors at all three time points to achieve full control of covariate influences (Little, 2013). Outcome favorability (a timevariant covariate) was regressed on the concurrent cognitive trust and process justice factors. We present results for nested models in Table 4. The resulting fit indices indicated that the models estimating over time relations either from process justice to subsequent cognitive trust (Model 2), or the opposite direction (Model 3), provided a better fit to the data than a model that only estimated autoregressive paths among cognitive trust and process justice (Model 1). However, the reciprocal model (Model 4) provided the best fit to our data as indicated by the chi-square difference tests.

As shown in Figure 2, the results of the reciprocal model indicated that planning stage process justice perceptions (T1) was positively related to subsequent post-merger cognitive trust (T2). However, the relationship between post-merger process justice (T2) and subsequent cognitive trust (T3) was not statistically significant. Accordingly, Hypothesis 1 was partially supported. The results also indicated that cognitive trust was positively related to subsequent process justice perceptions in both of the study's time intervals $(\mathrm{T} 1 \rightarrow \mathrm{T} 2, \&$ $\mathrm{T} 2 \rightarrow \mathrm{T} 3) .{ }^{5}$ Thus, Hypothesis 2 was fully supported. Furthermore, the results provided partial 
support for Hypothesis 3. Specifically, the justice $\rightarrow$ trust $\rightarrow$ justice reciprocal relationship was supported but the trust $\rightarrow$ justice $\rightarrow$ trust relationship was not supported as the relationship between justice at Time 2 and cognitive trust at Time 3 was not statistically significant.

\section{Discussion}

We investigated the dynamic interplay between two psychological constructs with noted significance in the context of organizational mergers: employees' perceptions of merger process justice and cognitive trust in the top management team. Prior research involving justice and trust-related constructs has overwhelmingly used cross-sectional designs that preclude conclusions regarding dynamic relations, including the direction of causal effects, between these constructs (Holtz, 2013). In order to improve upon extant research, this study used a cross-lagged longitudinal design spanning a two-year period before and after an organizational merger. Our findings have several important implications for management research and practice.

\section{Theoretical and Practical Implications}

This study answers calls for research directed at better understanding temporal relations between trust and justice constructs (e.g., Colquitt \& Rodell, 2011; Holtz, 2013). Our results suggest that merger process justice and cognitive trust have positive reciprocal relations over time. In particular, the cross-lagged analyses suggested that planning stage (T1) process justice perceptions were positively related to post-merger (T2) cognitive trust, which in turn influenced subsequent post-merger (T3) process justice perceptions, resulting in positive reciprocal relations. Similarly, planning stage (T1) cognitive trust was positively related to post-merger (T2) process justice perceptions. However, the influence of postmerger (T2) process justice perceptions on subsequent (T3) cognitive trust was not statistically significant. In terms of the relative strength of the observed relations, the 
cognitive trust-justice directional relationships were slightly (not significantly) stronger than the justice-cognitive trust relationships across the time points in this study.

These findings highlight the need for research to advance beyond focusing on unidirectional effects between justice and trust constructs because simple bivariate relations paint an incomplete and potentially erroneous picture of relationships between these constructs. For instance, meta-analytic estimates (derived predominantly from cross-sectional research studies) reveal strong correlations (in the $.50-70$ range) between justice and trust constructs (Colquitt et al., 2013; Rupp et al., 2014). Typically, such findings are viewed through the lens of social exchange theory and interpreted as evidence that perceived justice exerts a robust impact on trust-related cognitions. Consistent with past research, we found robust bivariate correlations between process justice perceptions and cognitive trust when assessed contemporaneously and even when assessed about one and two years apart, respectively (Table 1). However, the results of the cross-lagged longitudinal analyses revealed more modest effects (Figure 2). Failing to account for prior levels of the focal outcomes in this study would have overestimated the impact of justice perceptions on cognitive trust, and vice versa. Thus, our results illustrate the importance of accounting for prior levels of the focal dependent variable when a study is focused on justice-trust relations or trust-justice relations. Further, our findings also underscore prior warnings that it is an oversimplification for researchers to assume that justice is an antecedent, rather than a consequence, of trust-related cognitions (Colquitt \& Rodell, 2011; Lewicki et al., 2005).

This warning extends to management practitioners as well. For instance, in light of extant meta-analytic estimates, a practitioner of evidence-based management might conclude that an intervention designed to enhance justice perceptions will dramatically improve employee trust (Holtz, 2015). However, our study suggests that expectations for such robust effects are overly optimistic. For instance, we found that cognitive trust can exert just as 
strong (or stronger) effects on perceptions of justice, than the other way around. Thus, an existing belief that management is incompetent and unreliable, for example, will negatively color one's perceptions of managerial actions and reduce the potency of fairness interventions. Moreover, as we mentioned above, prior estimates involving justice-trust relations have largely been based on cross-sectional research. Our results illustrate that failing to control for prior trust-related cognitions when investigating the impact of justice on trustrelated cognitions will produce overly inflated results. To be clear, fostering favorable perceptions of justice is unquestionably important. However, in practice, the actual impact of any particular justice intervention on trust-related cognitions is likely to be less robust than is typically conveyed in the extant literature.

It is also interesting to note that, while the cognitive trust-process justice effects were relatively consistent across the duration of the study, the reverse relationship (process justicecognitive trust) was significant between Time 1 and Time 2 then did not reach conventional levels of significance between Time 2 and Time 3. Supplemental analyses suggested that this result was not due to the temporal stability of the constructs. ${ }^{6}$ Interestingly, uncertainty management theory (van den Bos, 2001) suggests that justice perceptions are especially salient during periods of major change and uncertainty in one's environment. Thus, the attenuated (Time 2-3) effect of process justice may be attributable to the fact that the changes were relatively minor by the second year of the merger and, consequently, process justice information as a signal of top management team's trust-related characteristics (i.e., cognitive trust) was no longer as salient to employees. Similarly, other researchers have noted that process justice perceptions may have stronger effects prior to, or soon after, one knows the outcome of a decision process and that the impact of procedural justice fades after the outcome is known (e.g., Ambrose \& Cropanzano, 2003; Maertz, Mosley, Bauer, Posthuma, \& Campion, 2004). 
This study also adds to our limited understanding of how psychological reactions unfold throughout a merger process (Monin et al., 2013; Nemanich \& Keller, 2007). On one hand, our results suggest that failing to adhere to principles of process justice (e.g., timely communication, consistent application of procedures) when planning and implementing significant change events, such as an organizational merger, may do significant damage to management's reputation for trustworthiness. On the other hand, our results suggest that failing to cultivate a reputation for being competent and reliable, can negatively bias employee perceptions of justice as a change event unfolds. Thus, it is important that organizational leaders work to instill favorable impressions of their competence and perceptions of justice throughout the duration of an important change event. These issues are particularly important as justice and trust constructs have been linked to a variety of outcomes critical to the success of change initiatives including greater decision acceptance, increased performance, less deviance, and reduced turnover intentions (e.g., Colquitt et al., 2013; Dirks \& Ferrin, 2002; Melkonian, Monin, \& Noorderhaven, 2011).

\section{Limitations}

Of course, our study is not without limitations. For instance, our data were collected using a self-report survey. As such, common method variance is a potential source of measurement error in this study (e.g., Podsakoff, MacKenzie, Lee, \& Podsakoff, 2003). That being said, we used a longitudinal design to minimize the risk of common method variance (Ostroff, Kinicki, \& Clark, 2002; Podsakoff et al., 2003) and the focal constructs of our study (trust and justice perceptions) necessitate the use of self-report measures.

Furthermore, in our longitudinal study design we were restricted to three measurement time points with one-year time lags. Shorter measurement time lags could produce stronger relations, be less vulnerable to interim effects, and capture potential fluctuations in the relations between trust-related cognitions and justice perceptions (e.g., 
Dormann \& van de Ven, 2014; Fortin et al., 2016; Little, 2013). Thus, future research with different longitudinal designs, such as more frequent measurement time points and longer time spans, are needed to further elucidate the relations between trust and justice.

Additionally, two contextual issues might have impacted the generalization of our results. First, as is typical during mergers and acquisitions, there were personnel changes in the top management team during our study (see Measures section). Thus, the focal entity associated with our cognitive trust measurement (i.e., the top management team) experienced changes across different time points. However, the established over time measurement invariance (Table 3) suggest that employees did not view the top management team as a fundamentally different entity at different time points. Furthermore, this conclusion is supported by the relative strong relations within the cognitive trust construct across time (Table $1 \&$ Figure 2). Second, the top management team in an organization is typically responsible for deciding whether a major organizational change should be executed or not. However, in the current study, the top management team was in charge of the planning and implementation of the merger but they were not actually responsible for the original merger decision made by politicians in a municipal council. In a context where the top management is also responsible for the initial merger decision, it is quite likely that employees' assessments on the soundness of the original merger decision shape their subsequent evaluations of top management team's competence and reliability (i.e., cognitive trust) and justice perceptions of the process. This contextual feature is unlikely to affect our main results, but it should be kept in mind when considering the generalization of our study's results over different organizational change contexts.

\section{Suggestions for Future Research}

First, future studies could investigate longitudinal relations between different trustrelated cognitions and justice perceptions. For example, in this study we chose not to measure 
affective trust as it is "grounded in reciprocated interpersonal care and concern" (McAllister, 1995, p. 25). Therefore, the referent of affective trust measurement should be an entity whom employees have direct contact with and with whom they are able to create close emotional and interpersonal relationships, such as an immediate supervisor, instead of the top management team of a large organization. Accordingly, future studies that incorporate alternative operationalizations of trust-related characteristics (e.g., integrity and benevolence evaluations), affective trust, and the psychological state of trust, may help to further clarify relations between trust-related cognitions and justice constructs.

Second, we tested aspects of the trust primacy model (Holtz, 2013), yet several key propositions remain untested. For instance, this model suggests that trustworthiness evaluations held with greater certainty should exert stronger effects on subsequent justice perceptions and may be more resistant to change over time. Long-tenured employees may often feel more certain about their evaluations concerning an entity's trust-related characteristics, but we suspect that certainty may also depend on the focus and type of these evaluations and the degree that an employee has direct first-hand observations. In our sample, and in most large organizations, evaluations of top management team's characteristics were likely inferred through secondhand information (e.g., word of mouth, formal policy announcements, etc.) as direct contact with the top management team is quite rare for most employees. Compared to characteristic evaluations of an employees' immediate supervisor, evaluations of the top management team are probably held with less certainty, and thus may be less impactful and less resistance to change over time. We recommend that research incorporating measures of both trust-related evaluation certainty and justice perception certainty may yield important insights into the dynamic relations between trust-related cognitions and justice constructs. 


\section{Conclusions}

Trust-related cognitions and justice constructs have been widely studied in the management literature, yet important questions regarding the reciprocal and causal relations between these variables remain unanswered (e.g., Colquitt \& Rodell, 2011; Holtz, 2013; Lewicki et al., 2005). In this study, we found evidence for reciprocal relationships between justice perceptions of a merger process and cognitive trust in the top management over time. Consistent with conventional wisdom, justice emerged as a significant antecedent of cognitive trust. On the other hand, cognitive trust was significantly associated with employees' subsequent perceptions of justice. In fact, the perspective that cognitive trust is an antecedent of process justice perceptions received somewhat stronger support than the view that cognitive trust represents an outcome of perceived justice. Therefore, the relations between cognitive trust and justice perceptions are more dynamic than has traditionally been conveyed in the management literature. 


\section{References}

Ambrose, M. L., \& Arnaud, A. (2005). Are procedural justice and distributive justice conceptually distinct? In J. Greenberg \& J. A. Colquitt (Eds.), Handbook of organizational justice (pp. 59-84). Mahwah, New Jersey: Lawrence Erlbaum Associates.

Ambrose, M. L., \& Cropanzano, R. (2003). A longitudinal analysis of organizational fairness: An examination of reactions to tenure and promotion decisions. Journal of Applied Psychology, 88(2), 266-275. doi:10.1037/0021-9010.88.2.266

Ambrose, M. L., \& Schminke, M. (2009). The role of overall justice judgments in organizational justice research: A test of mediation. Journal of Applied Psychology, 94(2), 491-500. doi:10.1037/a0013203

Andersson, L. M., \& Pearson, C. M. (1999). Tit for tat? The spiraling effect of incivility in the workplace. Academy of Management Review, 24(3), 452-471.

doi:10.5465/amr.1999.2202131

Blader, S. L., \& Tyler, T. (2005). How can theories of organizational justice explain the effects of fairness? In J. Greenberg \& J. A. Colquitt (Eds.), Handbook of organizational justice (pp. 329-354). Mahwah, New Jersey: Lawrence Erlbaum Associates.

Blau, P. (1964). Exchange and power in social life. New York: Wiley.

Bobocel, D. R., \& Gosse, L. (2015). Procedural justice: A historical review and critical analysis. In R. Cropanzano \& M. L. Ambrose (Eds.), Oxford handbook of justice in the workplace (pp. 51-88). New York: Oxford University Press.

Brockner, J., Siegel, P. A., Daly, J. P., Tyler, T., \& Martin, C. (1997). When trust matters: The moderating effect of outcome favorability. Administrative Science Quarterly, 42(3), 558-583. doi:10.2307/2393738 
Brockner, J., Wiesenfeld, B. M., \& Diekmann, K. A. (2009). Towards a "fairer" conception of process fairness: Why, when and how more may not always be better than less. The Academy of Management Annals, 3(1), 183-216. doi:10.1080/19416520903047228

Byrne, B. (2012). Structural equation modeling with Mplus: Basic concepts, applications, and programming. New York: Routledge.

Chan, M. E., \& McAllister, D. J. (2014). Abusive supervision through the lens of employee state paranoia. Academy of Management Review, 39(1), 44-66. doi:10.5465/amr.2011.0419

Cohen-Charash, Y., \& Spector, P. E. (2001). The role of justice in organizations: A metaanalysis. Organizational Behavior and Human Decision Processes, 86(2), 278-321. doi:10.1006/obhd.2001.2958

Cole, D. A., \& Maxwell, S. E. (2003). Testing mediational models with longitudinal data: Questions and tips in the use of structural equation modeling. Journal of Abnormal Psychology, 112(4), 558-577. doi:10.1037/0021-843X.112.4.558

Colquitt, J. A., \& Rodell, J. B. (2011). Justice, trust, and trustworthiness: A longitudinal analysis integrating three theoretical perspectives. Academy of Management Journal, 54(6), 1183-1206. doi:10.5465/amj.2007.0572

Colquitt, J. A., \& Rodell, J. B. (2015). Measuring justice and fairness. In R. Cropanzano \& M. L. Ambrose (Eds.), Oxford handbook of justice in the workplace (pp. 187-202). New York: Oxford University Press.

Colquitt, J. A., Scott, B. A., \& LePine, J. A. (2007). Trust, trustworthiness, and trust propensity: A meta-analytic test of their unique relationships with risk taking and job performance. Journal of Applied Psychology, 92(4), 909-927. doi:10.1037/00219010.92.4.909 
Colquitt, J. A., Scott, B. A., Rodell, J. B., Long, D. M., Zapata, C. P., Conlon, D. E., \& Wesson, M. J. (2013). Justice at the millennium, a decade later: A meta-analytic test of social exchange and affect-based perspectives. Journal of Applied Psychology, 98(2), 199-236. doi:10.1037/a0031757

Colquitt, J. A., \& Shaw, J. C. (2005). How should organizational justice be measured? In J. Greenberg \& J. A. Colquitt (Eds.), Handbook of organizational justice (pp. 113-152). Mahwah, New Jersey: Lawrence Erlbaum Associates.

Colquitt, J. A., \& Zipay, K. P. (2015). Justice, fairness, and employee reactions. Annual Review of Organizational Psychology and Organizational Behavior, 2(1), 75-99. doi:10.1146/annurev-orgpsych-032414-111457

Cook, K. S. (2005). Networks, norms, and trust: The social psychology of social capital. Social Psychology Quarterly, 68(1), 4-14. doi: 10.1177/019027250506800102

Cropanzano, R., \& Mitchell, M. S. (2005). Social exchange theory: An interdisciplinary review. Journal of Management, 31(6), 874-900. doi:10.1177/0149206305279602

Cropanzano, R., \& Rupp, D. E. (2008). Social exchange theory and organizational justice. In S. W. Gilliland, D. Skarlicki, \& D. D. Steiner (Eds.), Justice, morality, and social responsibility (pp. 63-99). Greenwich, CT: Information Age Publishing.

Dirks, K. T., \& Ferrin, D. L. (2001). The role of trust in organizational settings. Organization Science, 12(4), 450-467. doi:10.1287/orsc.12.4.450.10640

Dirks, K. T., \& Ferrin, D. L. (2002). Trust in leadership: Meta-analytic findings and implications for research and practice. Journal of Applied Psychology, 87(4), 611628. doi:10.1037/0021-9010.87.4.611

Dormann, C., \& van de Ven, B. (2014). Timing in methods for studying psychosocial factors at work. In F. M. Dollard, A. Shimazu, R. Bin Nordin, P. Brough, \& R. M. Tuckey 
(Eds.), Psychosocial factors at work in the Asia Pacific (pp. 89-116). Dordrecht: Springer Netherlands.

Evans, J. S. B. T. (1989). Bias in human reasoning: Causes and consequences. Hove: Lawrence Erlbaum.

Farrell, A. D. (1994). Structural equation modeling with longitudinal data: Strategies for examining group differences and reciprocal relationships. Journal of Consulting and Clinical Psychology, 62(3), 477-487. doi:10.1037/0022-006X.62.3.477

Ferguson, A. J., \& Peterson, R. S. (2015). Sinking slowly: Diversity in propensity to trust predicts downward trust spirals in small groups. Journal of Applied Psychology, 100(4), 1012-1024. doi:10.1037/ap10000007

Fiske, S. T., \& Taylor, S. E. (1991). Social cognition. New York: McGraw-Hill.

Fortin, M., Cojuharenco, I., Patient, D., \& German, H. (2016). It is time for justice: How time changes what we know about justice judgments and justice effects. Journal of Organizational Behavior, 37(1), 30-56. doi:10.1002/job.1958

Gambetta, D. (1988). Can we trust trust? In D. Gambetta (Ed.), Trust: Making and breaking cooperative relations (pp. 213-237). New York: Basil Blackwell.

Giessner, S., Ullrich, J., \& van Dick, R. (2012). A social identity analysis of mergers and acquisitions. In D. Faulkner, S. Teerikangas, \& R. J. Joseph (Eds.), The handbook of mergers and acquisitions (pp. 474-494). New York: Oxford University Press.

Goodman, J. S., \& Blum, T. C. (1996). Assessing the non-random sampling effects of subject attrition in longitudinal research. Journal of Management, 22(4), 627-652. doi:10.1177/014920639602200405

Greenberg, J. (2001). Setting the justice agenda: Seven unanswered questions about "What, why, and how". Journal of Vocational Behavior, 58(2), 210-219. doi:10.1006/jvbe.2001.1792 
Holtz, B. C. (2013). Trust primacy: A model of the reciprocal relations between trust and perceived justice. Journal of Management, 39(7), 1891-1923. doi:10.1177/0149206312471392

Holtz, B. C. (2015). From first impression to fairness perception: Investigating the impact of initial trustworthiness beliefs. Personnel Psychology, 68(3), 499-546. doi:10.1111/peps.12092

Holtz, B. C., \& Harold, C. M. (2009). Fair today, fair tomorrow? A longitudinal investigation of overall justice perceptions. Journal of Applied Psychology, 94(5), 1185-1199. doi:10.1037/A0015900

Janssen, O. (2004). How fairness perceptions make innovative behavior more or less stressful. Journal of Organizational Behavior, 25(2), 201-215. doi:10.1002/job.238

Kramer, R. (2009). Rehinking trust. Harvard Business Review, 87, 69-77.

Lewicki, R. J., Wiethoff, C., \& Tomlinson, E. (2005). What is the role of trust in organizational justice? In J. Greenberg \& J. A. Colquitt (Eds.), Handbook of organizational justice (pp. 247-272). Mahwah, New Jersey: Lawrence Erlbaum Associates.

Li, P. P. (2012). When trust matters the most: The imperatives for contextualising trust research. Journal of Trust Research, 2(2), 101-106. doi:10.1080/21515581.2012.708494

Lind, E. A. (2001). Fairness heuristics theory: Justice judgments as pivotal cognitions in organizational relations. In J. Greenberg \& R. Cropanzano (Eds.), Advances in organizational justice (pp. 56-88). Stanford, CA: Stanford University Press.

Lind, E. A., \& Tyler, T. R. (1988). The social psychology of procedural justice. New York: Plenum Press. 
Lines, R., Selart, M., Espedal, B., \& Johansen, S. T. (2005). The production of trust during organizational change. Journal of Change Management, 5(2), 221-245. doi:10.1080/14697010500143555

Little, T. D. (2013). Longitudinal structural equation modeling. New York: The Guilford Press.

Maertz, C. P., Mosley, D. C., Bauer, T. N., Posthuma, R. A., \& Campion, M. A. (2004). Do procedural justice perceptions in a selection testing context predict applicant attraction and intention toward the organization? Journal of Applied Social Psychology, 34(1), 125-145. doi:10.1111/j.1559-1816.2004.tb02540.x

Mansour-Cole, D. M., \& Scott, S. G. (1998). Hearing it through the grapevine: The influence of source, leader-relations, and legitimacy on survivors' fairness perceptions. Personnel Psychology, 51(1), 25-54. doi:10.1111/j.1744-6570.1998.tb00715.x

Mayer, R. C., \& Davis, J. H. (1999). The effect of the performance appraisal system on trust for management: A field quasi-experiment. Journal of Applied Psychology, 84(1), 123-136. doi:10.1037/0021-9010.84.1.123

Mayer, R. C., Davis, J. H., \& Schoorman, F. D. (1995). An integrative model of organizational trust. Academy of Management Review, 20(3), 709-734. doi:10.5465/amr.1995.9508080335

McAllister, D. J. (1995). Affect- and cognition-based trust as foundations for interpersonal cooperation in organizations. Academy of Management Journal, 38(1), 24-59. doi:10.2307/256727

McEvily, B., \& Tortoriello, M. (2011). Measuring trust in organisational research: Review and recommendations. Journal of Trust Research, 1(1), 23-63. doi:10.1080/21515581.2011.552424 
Melkonian, T., Monin, P., \& Noorderhaven, N. G. (2011). Distributive justice, procedural justice, exemplarity, and employees' willingness to cooperate in M\&A integration processes: An analysis of the Air France-KLM merger. Human Resource Management, 50(6), 809-837. doi:10.1002/hrm.20456

Molm, L. D., Takahashi, N., \& Peterson, G. (2000). Risk and trust in social exchange: An experimental test of a classical proposition. American Journal of Sociology, 105(5), 1396-1427. doi:10.1086/210434

Monin, P., Noorderhaven, N., Vaara, E., \& Kroon, D. (2013). Giving sense to and making sense of justice in postmerger integration. Academy of Management Journal, 56(1), 256-284. doi:10.5465/amj.2010.0727

Moorman, R. H. (1991). Relationship between organizational justice and organizational citizenship behaviors: Do fairness perceptions influence employee citizenship? Journal of Applied Psychology, 76(6), 845-855. doi:10.1037/0021-9010.76.6.845

Moorman, R. H., \& Byrne, Z. S. (2005). How does organizational justice affect organizational citizenship behavior? In J. Greenberg \& J. A. Colquitt (Eds.), Handbook of organizational justice (pp. 355-382). Mahwah, New Jersey: Lawrence Erlbaum Associates.

Muthén, L. K., \& Muthén, B. O. (2012). Mplus user's guide: Statistical analysis with latent variables. Los Angeles, CA: Muthén \& Muthén.

Nemanich, L. A., \& Keller, R. T. (2007). Transformational leadership in an acquisition: A field study of employees. The Leadership Quarterly, 18(1), 49-68. doi:10.1016/j.leaqua.2006.11.003

Nickerson, R. S. (1998). Confirmation bias: A ubiquitous phenomenon in many guises. Review of General Psychology, 2(2), 175-220. doi:10.1037/1089-2680.2.2.175 
Ostroff, C., Kinicki, A. J., \& Clark, M. A. (2002). Substantive and operational issues of response bias across levels of analysis: An example of climate-satisfaction relationships. Journal of Applied Psychology, 87(2), 355-368. doi:10.1037//00219010.87 .2 .355

Ployhart, R. E., \& Vandenberg, R. J. (2010). Longitudinal research: The theory, design, and analysis of change. Journal of Management, 36(1), 94-120. doi:10.1177/0149206309352110

Podsakoff, P. M., MacKenzie, S. B., Lee, J.-Y., \& Podsakoff, N. P. (2003). Common method biases in behavioral research: A critical review of the literature and recommended remedies. Journal of Applied Psychology, 88(5), 879-903. doi:10.1037/00219010.88 .5 .879

Robinson, S. L. (1996). Trust and breach of the psychological contract. Administrative Science Quarterly, 41(4), 574-599. doi:10.2307/2393868

Rousseau, D. M., Sitkin, S. B., Burt, R. S., \& Camerer, C. (1998). Not so different after all: A cross-discipline view of trust. Academy of Management Review, 23(3), 393-404. doi:10.5465/amr.1998.926617

Rupp, D. E., Shao, R., Jones, K. S., \& Liao, H. (2014). The utility of a multifoci approach to the study of organizational justice: A meta-analytic investigation into the consideration of normative rules, moral accountability, bandwidth-fidelity, and social exchange. Organizational Behavior and Human Decision Processes, 123(2), 159-185. doi:10.1016/j.obhdp.2013.10.011

Satorra, A., \& Bentler, P. (2001). A scaled difference chi-square test statistic for moment structure analysis. Psychometrika, 66(4), 507-514. doi:10.1007/BF02296192

Schminke, M., Cropanzano, R., \& Rupp, D. E. (2002). Organization structure and fairness perceptions: The moderating effects of organizational level. Organizational Behavior 
and Human Decision Processes, 89(1), 881-905. doi:10.1016/S0749-5978(02)000341

Shapiro, D. L., \& Kirkman, B. L. (2001). Anticipatory injustice: The consequences of expecting injustice in the workplace. In J. Greenberg \& R. Cropanzano (Eds.), Advances in organizational justice. Stanford, CA: Stanford University Press.

Snyder, M., \& Swann, W. B. (1978). Hypothesis-testing processes in social interaction. Journal of Personality and Social Psychology, 36(11), 1202-1212. doi:10.1037/00223514.36.11.1202

Stahl, G. K., Larsson, R., Kremershof, I., \& Sitkin, S. B. (2011). Trust dynamics in acquisitions: A case survey. Human Resource Management, 50(5), 575-603. doi:10.1002/hrm.20448

Sutter, M., \& Kocher, M. G. (2007). Trust and trustworthiness across different age groups. Games and Economic Behavior, 59(2), 364-382. doi:10.1016/j.geb.2006.07.006

Tyler, T. R., \& De Cremer, D. (2005). Process-based leadership: Fair procedures and reactions to organizational change. The Leadership Quarterly, 16(4), 529-545. doi:10.1016/j.leaqua.2005.06.001

van den Bos, K. (2001). Uncertainty management: The influence of uncertainty salience on reactions to perceived procedural fairness. Journal of Personality and Social Psychology, 80(6), 931-941. doi:10.1037/0022-3514.80.6.931

Vandenberg, R. J., \& Lance, C. E. (2000). A review and synthesis of the measurement invariance literature: Suggestions, practices, and recommendations for organizational research. Organizational Research Methods, 3(1), 4-70.

doi:10.1177/109442810031002 


\section{Footnotes}

${ }^{1}$ Distributive justice was not included in the study because employees did not have requisite information regarding the eventual outcomes of the merger process before the merger came into effect. Thus, as we focused on the time-lagged effects of fairness perceptions throughout a merger, at three time points including the planning stage (Time 1), investigation of distributive justice perceptions would have been unsuitable for this purpose.

${ }^{2}$ To investigate whether subject attrition led to non-random sampling, we tested whether the probability of remaining in the sample at the later time points could be predicted by the variables from prior time points following the guidelines presented by Goodman and Blum (1996). The results indicated the possible non-random sampling did not affect the main results of this study.

${ }^{3}$ In the choice of measurement for cognitive trust in the top management team, we preferred the measurement by Mayer and Davis (1999) over the measurement developed by McAllister (1995). This was due to the latter being designed and worded to measure trust between managers (peers), and the former was designed to measure employees' assessment of top management. Thus, we found the measurement by Mayer and Davis to be more suitable for the context of our study. As the referent of the measurement, we chose to use the head of the organization and heads of divisions as they were the people who formed the top management team where the major decisions concerning the planning and implementation of the merger were made. Before the merger, the top management team for the two merging organizations consisted 8 and 6 persons respectively. The top management team of the merged organization consisted 7 persons.

${ }^{4}$ We also tested an alternative confirmatory factor analysis model that loaded interactional (i.e., interpersonal and informational) justice items, procedural justice items, and cognitive trust items on to three separate factors. The results indicated that the three-factor 
model provided a slightly better fit to the data, $\chi^{2}(339)=450.10, p<.001$, CFA $=.99$, TLI $=$ .99, RMSEA $=.02$, SRMR $=.02$, relative to the two-factor model. Notwithstanding the potential improvement in fit statistics, we elected to focus on a single process justice factor because a) there is currently no theoretical reason to expect differential relations between cognitive trust and procedural and interactional justice facets (Holtz, 2013), and b) empirical guidelines suggest that it is prudent to combine justice facets when facet correlations exceed .70 (Colquitt \& Shaw, 2005). In the current study, if we create separate factors for procedural and interactional justice, the within-time correlation between these factors range from .93 to .95 at different the time points. Additionally, we conducted all our analyses with separating the procedural and interactional justice facets and the results of our hypothesis tests are nearly identical whether, or not, the justice constructs are aggregated (the results can be obtained from the first author).

${ }^{5}$ As the results in Figure 2 indicated difference in over time cross-lagged effects between process justice and cognitive trust, we conducted further analyses to test whether these differences were statistically significant. Model comparison results indicated that the path coefficients over the first time interval, process justice (T1) to cognitive trust (T2) and cognitive trust (T1) to process justice (T2), were not statistically significantly different from each other, $\Delta \chi^{2}(1)=0.80, p=.778$. The difference between the cross-lagged path estimates over the second time interval $(\mathrm{T} 2 \rightarrow \mathrm{T} 3)$ was marginally statistically significant, $\Delta \chi^{2}(1)=3.23$, $p=.072$. Taken together with the results in Table 4, which indicated slightly better model fit for cognitive trust to process justice (Model 3) than for process justice to cognitive trust (Model 2), we conclude that our results indicated slightly, however not statistically significantly, stronger support for Hypothesis 2 of cognitive trust being positively related to subsequent process justice than for Hypothesis 1 of the opposite relation. 
${ }^{6}$ In longitudinal cross-lagged models the more stable variable (i.e., a variable with less change over time) is more likely to predict the less stable variable due to a larger residual of the less stable variable (e.g., Farrell, 1994; Little, 2013). To examine whether our findings were affected by the difference in the over time stability of merger process justice or cognitive trust factors, we compared the autoregressive paths among both variables. The results show that when we set the autoregressive paths equal between consequent points of time among process justice and cognitive trust, the model was not statically significantly different in comparison to a model where these paths were freely estimated, $\Delta \chi^{2}(2)=3.25, p$ $=.197$. This result indicates that the stabilities of the process justice and cognitive trust did not differ statistically significantly. Thus, there was no indication that the main results of our study would have been affected by the differing amounts of over time stability between the focal constructs.

${ }^{7}$ When referring to the merger process in the process justice and outcome favorability measurements' instructions, we used the wording of "founding" of the new organization. This decision was based upon our discussions with the organizations' representatives when planning and piloting the questionnaire. The representatives suggested to use wording which is common in the organization(s) and which would be perceived as neutral among the participants to minimize negative reactions, feelings or misgivings towards the survey. 
Table 1

Means, Standard Deviations, and Zero-Order Correlations

\begin{tabular}{|c|c|c|c|c|c|c|c|c|c|c|c|c|c|c|}
\hline Variable & Scale & $M$ & $S D$ & 1 & 2 & 3 & 4 & 5 & 6 & 7 & 8 & 9 & 10 & 11 \\
\hline $\begin{array}{l}\text { 1. Cognitive trust } \\
\text { (T1) }\end{array}$ & $1-5$ & 3.00 & 0.91 & $(.93)$ & & & & & & & & & & \\
\hline $\begin{array}{l}\text { 2. Cognitive trust } \\
\text { (T2) }\end{array}$ & $1-5$ & 2.80 & 0.84 & $.68 * * *$ & $(.91)$ & & & & & & & & & \\
\hline $\begin{array}{l}\text { 3. Cognitive trust } \\
\text { (T3) }\end{array}$ & $1-5$ & 2.58 & 0.88 & $.57 * * *$ & $.73 * * *$ & $(.92)$ & & & & & & & & \\
\hline $\begin{array}{l}\text { 4. Process justice } \\
\text { (T1) }\end{array}$ & $1-5$ & 2.30 & 0.83 & $.47 * * *$ & $.48 * * *$ & $.41 * * *$ & $(.87)$ & & & & & & & \\
\hline $\begin{array}{l}\text { 5. Process justice } \\
\text { (T2) }\end{array}$ & $1-5$ & 2.33 & 0.79 & $.51 * * *$ & $.69 * * *$ & $.56 * * *$ & $.70 * * *$ & $(.87)$ & & & & & & \\
\hline $\begin{array}{l}\text { 6. Process justice } \\
\text { (T3) }\end{array}$ & $1-5$ & 2.47 & 0.80 & $.50 * * *$ & $.63 * * *$ & $.75 * * *$ & $.55 * * *$ & $.71 * * *$ & (.88) & & & & & \\
\hline $\begin{array}{l}\text { 7. Outcome } \\
\text { favorability (T2) }\end{array}$ & $1-7$ & 3.42 & 1.52 & $.26 * * *$ & $.32 * * *$ & $.23 * * *$ & $.28 * * *$ & $.43 * * *$ & $.32 * * *$ & - & & & & \\
\hline $\begin{array}{l}\text { 8. Outcome } \\
\text { favorability (T3) }\end{array}$ & $1-7$ & 3.53 & 1.41 & $.27 * * *$ & $.32 * * *$ & $.41 * * *$ & $.24 * * *$ & $.33 * * *$ & $.47 * * *$ & $.32 * * *$ & - & & & \\
\hline $\begin{array}{l}\text { 9. } \begin{array}{l}\text { Pre-merger } \\
\text { organization }^{\mathrm{a}}\end{array}\end{array}$ & $0 / 1$ & 0.43 & 0.50 & $.28 * * *$ & $.19 * * *$ & $.09 *$ & $.31 * * *$ & $.26 * * *$ & $.12 * *$ & .03 & .00 & - & & \\
\hline $\begin{array}{l}\text { 10. Position in the } \\
\text { organization }^{\mathrm{b}}\end{array}$ & $0 / 1$ & 0.24 & 0.43 & $.21 * * *$ & $.14 * *$ & $.13^{* *}$ & .03 & .02 & $.09 *$ & .06 & .06 & -.04 & - & \\
\hline 11. Age & $20-69$ & 47.5 & 19.4 & $.14 * * *$ & .08 & .01 & .04 & -.01 & .04 & .01 & -.03 & .01 & $.16^{* * *}$ & - \\
\hline
\end{tabular}

Note. $N=622 . \mathrm{T} 1=$ Time $1 ; \mathrm{T} 2=$ Time $2 ; \mathrm{T} 3=$ Time 3 . Cognitive trust $=$ Cognitive trust in the top management. Process justice $=$

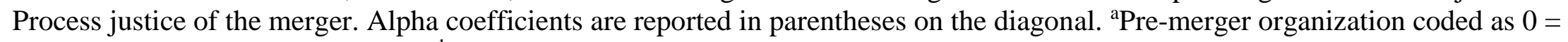
organization $A, 1=$ organization $B$. ${ }^{b}$ Position in the organization coded as $0=$ employee, $1=$ supervisor or middle management. $* p<.05 . * * p<.01 . * * * p<.001$. 
Table 2

Confirmatory Factor Analysis of Measurement Model

Item loadings

(T1/T2/T3)

Process justice of the merger

1. The rules of procedures have been applied consistently across people and situations.

$.68 / .61 / .69$

2. All parties that are affected by the decisions have had opportunities to express their concerns.

3. The decisions have been based on accurate information.

$.82 / .80 / .83$

4. Feedback and information have been provided regarding the impacts of decisions.

$.69 / .71 / .67$

5. Employees have been treated with dignity during the founding process.

$.81 / .81 / .80$

6. Honest explanations have been given for the decisions made concerning the founding of (the new organization).

Cognitive trust in the top management

1. Top management is very capable of performing its job.

$.85 / .86 / .86$

2. Top management is known to be successful at the things it tries to do.

$.81 / .81 / .81$

3. I feel very confident about top management's skills.

$.93 / .90 / .91$

4. Top management is well qualified.

$.92 / .84 / .87$

Note. $N=622 . \mathrm{T} 1=$ Time $1 ; \mathrm{T} 2=$ Time $2 ; \mathrm{T} 3=$ Time 3 . Completely standardized maximum likelihood robust parameter estimates. All estimates are $p<.001$. 
Table 3

Tests of Measurement Invariance Over Time

\begin{tabular}{lcccccccc}
\hline \multicolumn{1}{c}{ Model } & $\chi^{2}$ & $d f$ & CFI & TLI & RMSEA & SRMR & $\Delta \chi^{2}$ & $p$ \\
\hline Configural $^{\mathrm{a}}$ & $535.70^{* * *}$ & 360 & .98 & .98 & .03 & .03 & & \\
& & & & & & & & \\
Weak invariance $^{\mathrm{b}}$ & $560.13^{* * *}$ & 376 & .98 & .98 & .03 & .04 & 24.52 & .079 \\
& & & & & & & & \\
Partial strong invariance $^{\mathrm{c}}$ & $573.87^{* * *}$ & 388 & .98 & .98 & .03 & .04 & 13.50 & .334 \\
\hline
\end{tabular}

Note. $N=622$. CFI = comparative fit index, TLI= Tucker-Lewis fit index, RMSEA= Root mean square error of approximation, $\mathrm{SRMR}=$ standardized root mean square residual. Model comparisons computed with the Satorra-Bentler scaled chi-square difference test. ${ }^{a} \mathrm{~A}$ model without constraints. ${ }^{\mathrm{b}} \mathrm{A}$ model with items' factor loadings set equal over time. ' A model with items' factor loadings and intercepts set equal over time.

$* * * p<.001$ 
Table 4

Fit Statistics for Nested Over Time Models

\begin{tabular}{|c|c|c|c|c|c|c|c|c|c|}
\hline Model & $\chi^{2}$ & $d f$ & CFI & TLI & RMSEA & SRMR & Comparison & $\Delta \chi^{2}$ & Preference \\
\hline M1.Autoregressive paths only ${ }^{\mathrm{a}}$ & $944.99 * * *$ & 531 & .97 & .96 & .04 & .11 & & & \\
\hline M2.Process Justice $\rightarrow$ Cognitive trust $^{\mathrm{b}}$ & $902.77 * * *$ & 529 & .97 & .97 & .03 & .09 & M2-M1 & $43.55^{* * *}$ & M2 \\
\hline M3. Cognitive trust $\rightarrow$ Process justice ${ }^{c}$ & $877.64 * * *$ & 529 & .97 & .97 & .03 & .09 & M3-M1 & $60.31 * * *$ & M3 \\
\hline \multirow[t]{3}{*}{ M4.Reciprocal (cross-lagged) ${ }^{\mathrm{d}}$} & $852.43 * * *$ & 527 & .97 & .97 & .03 & .08 & M4-M1 & $86.64 * * *$ & M4 \\
\hline & & & & & & & M4-M2 & $43.14 * * *$ & M4 \\
\hline & & & & & & & M4-M3 & $24.69 * * *$ & M4 \\
\hline
\end{tabular}

Note. $N=622$. Process justice $=$ Process justice of the merger. Cognitive trust $=$ Cognitive trust in top management. CFI = comparative fit index, TLI= Tucker-Lewis fit index, RMSEA= Root mean square error of approximation,

$\mathrm{SRMR}=$ standardized root mean square residual. Model comparisons computed with the Satorra-Bentler scaled chi-

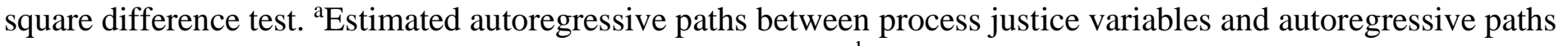
between cognitive trust variables across the three time points. ${ }^{b}$ Estimated autoregressive paths and paths between justice at Time 1 and cognitive trust at Time 2 and between justice at Time 2 and cognitive trust at Time 3 . ${ }^{c}$ Estimated autoregressive paths and paths between cognitive trust at Time 1 and justice at Time 2 and between cognitive trust at Time 2 and justice at Time $3 .{ }^{\mathrm{d}}$ Combined all the paths estimated in the previous models. $* * * p<.001$ 


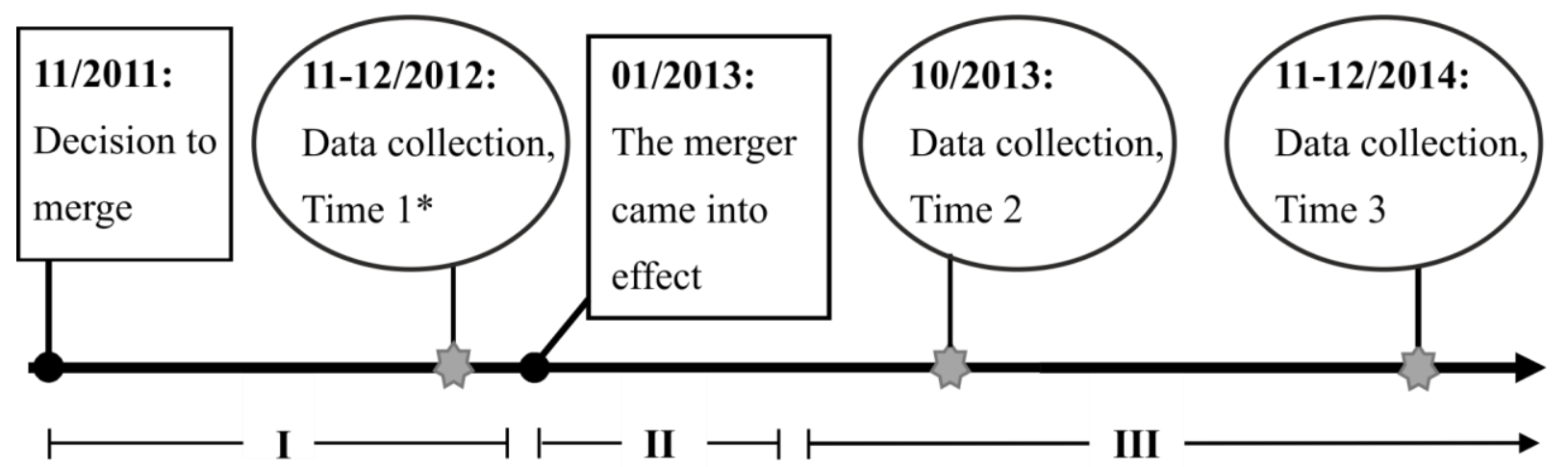

Phase I: Preparation and Phase II: Main changes planning (13 months):

- Planning of the new organizational structure.

- Personnel participated in the planning process in committees, seminars, and intranet discussion forums.

- Introduction of the new organizational structure (i.e., the integration of services provided by the two pre-merge organizations) and new service regulations.
(6 months):

- Implementation of the new organizational structure and integration of services.

- The main changes for the personnel (i.e., job description, location in the organization, supervisors) took place.
Phase III: Minor changes (continuous):

- Smaller changes and adjustments in the lowerlevel organizational structure (i.e., integration of services continues, planning, testing, and implementation of new operations models).

* At Time 1, data collection ended at 12th of December, 2012.

Figure 1. Timeline of the merger process. 


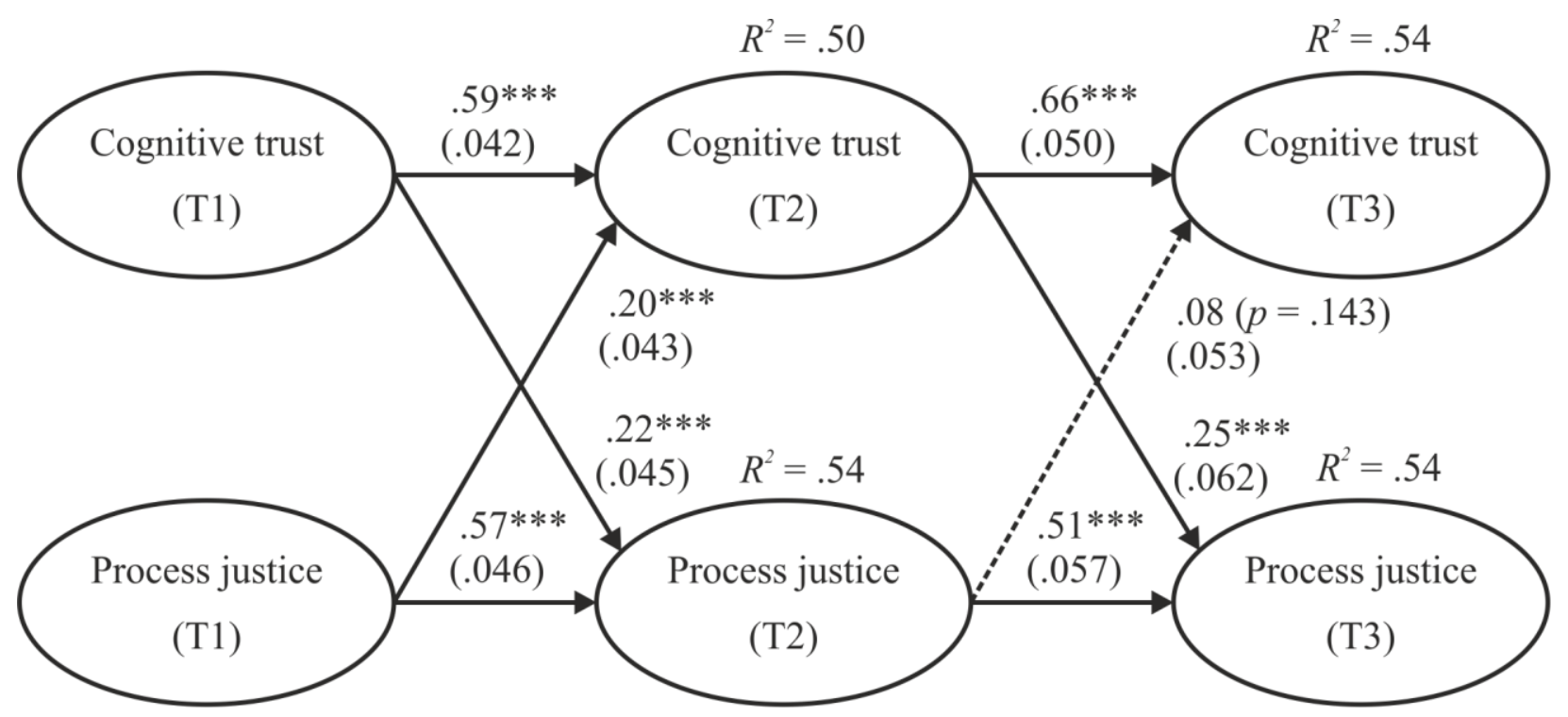

Figure 2. Cross-lagged structural equation modeling results testing the reciprocal over time relationships between cognitive trust in the top management and perceptions of merger process justice. $\mathrm{T} 1=$ Time $1 ; \mathrm{T} 2=$ Time 2 ; T3 = Time 3 . Completely standardized maximum likelihood robust parameter estimates are reported. Standard deviations are presented in parentheses. Excluded from the figure for clarity are paths from covariates (pre-merger organization, position in the organization, age, outcome favorability), latent factors' items, and within-time covariances among latent variables.

$* * * p<.001$ 


\section{Appendix}

\section{Construct items and instructions}

Process justice. Items adapted from Mansour-Cole and Scott (1998) and Moorman (1991).

Participants were given the following instructions preceding the set of items: "The following statements address your views on the procedures and decision-making in general [during the past year] related to the foundation process of (the new organization). ${ }^{.7}$ The temporal reference in brackets was included at $\mathrm{T} 2$ and $\mathrm{T} 3$ time points. The items were assessed on a 5-point scale $(1=$ completely disagree; $5=$ completely agree).

1. The rules of procedures have been applied consistently across people and situations.

2. All parties that are affected by the decisions have had opportunities to express their concerns.

3. The decisions have been based on accurate information.

4. Feedback and information have been provided regarding the impacts of decisions.

5. Employees have been treated with dignity during the founding process.

6. Honest explanations have been given for the decisions made concerning the founding of (the new organization).

Cognitive trust in the top management. Adapted from Mayer and Davis (1999).

Participants were given the following instructions preceding the set of items: "The following statements concern the top management of (the organization). By top management we refer to the head of (the organization) and heads of divisions". The items were assessed on a 5-point scale $(1=$ completely disagree; $5=$ completely agree $)$.

1. Top management is very capable of performing its job.

2. Top management is known to be successful at the things it tries to do. 
3. I feel very confident about top management's skills.

4. Top management is well qualified.

Outcome favorability. The following item was used to assess outcome favorability: "When you think about all the changes that the founding of (the new organization) ${ }^{7}$ has brought about, how would you characterize the changes which have taken place thus far in your own work? Choose the alternative that best describes your opinion. The changes have been $1=$ mostly negative, ..., $7=$ mostly positive." 